\title{
Minireview
}

\section{Unexpected intron location in non-vertebrate globin genes}

\author{
Luc Moens", Jacques Vanfleteren', Ivo De Baere", Anna M. Jellie', Warren Tate ${ }^{\mathrm{c}}$ and \\ Clive N.A. Trotmanc \\ "Department of Biocitemistry, University of Antwerp, Universiteitsplein 1, B-2610 Antwerp, Belgium, 'Laboratory of Animal \\ Morphology and Systematics, Liniversity of Ghent, K.L. Ledeganckstraat 35, B=9000 Ghent, Belgium and 'Deparment of \\ Bioctiemistry, University of Olago, Dunedin, New Zealand
}

Received 14 August 1992; revised version received 18 September 1992

The Cnenorhabditis elegans and Arremia T4 globin sequences are highly homologous with wher invertebrate globins. The intron/exon patterns of their genes display a single intron in the $E$ and $G$ heliees respectively. Precoding introns in multirepeat globins are inserted in homologous positions. Comparison of the intron/exon patrens in the known globin gene sequences demonstrates that they are more diverse than first expected but nevertheless can be derived from an ancestral pattern having 3 introns and 4 exons.

Globin genc; Intron location; Evolution

\section{INTRODUCTION}

Vertebrate globin genes invariably have two introns resulting in three exons with boundaries between amino acid residues $B 12$ and $B 13$ and between $G 6$ and $G 7$ (helix notation). Plant globin genes have an extra intron between E14 and E15, making four exons, whereas most insect globin genes contain no intervening sequences $[1,2]$. It is currently thought that the 4 exons, 3 introns arrangement is ancestral and that evolution has sometimes led to the elimination of introns [1-3].

Recently the gene sequence of the internally duplicated globin from the nematode Pseucioterranola decipiens was described [4]. This sequence contains six introns and seven exons altogether. The first intron separates a secretory peptide leader sequence from the functional protein coding sequence (precoding intron). The next three introns are in the $B, E$ and $G$ helix coding sequences similar to plants. The fifth intron separates the two globin repeats (bridge intron) and the final one is found in the second iepeat wihich has retained only this single intron in the $B$ helix.

The globin of the clam Barbatia reeveana (Mollusca) also has a duplicated globin structure but has the vertebrate intron-exon fattern, together with a precoding intron before the first repeat and a bridge intron between the repeats [5].

This contrast suggests that the giobin gene structure

Correspondence address: L. Moens, Department of Bicchemistry, University of Antwerp, Universiteitsplein 1, B-2610 Antwerp, Belgium. Fax: (32) (3) 8202248 . of invertebrates is more diverse than at first expected.

Here we examine the protein and gene structures of the monomeric haenoglobin of the nematode Caen. orhabditis elegans and repeat $T A$ of the multi-repeat globin of the crustacenn Artemia and we evaluate their globin gene structures from an evolutionary perspective.

\section{ALIGNMENT OF GLOBIN AMINO ACID SEQUENCES}

The proper alignment of the translated globin sequences is a prerequisite for the assessment of equivalent intron positions. The invertebrate globin sequences from which the genomic structures are known are aligned in Fig. 1.

Only the alignment of the $C$. elegans globin is discussed in detail below. The stereochemical interpretation of the other sequences has been published previously [11-17].

The proposed aligninent recognizes the obligatory CD1 Phe and F8 His, as well as the conservation of the Gly at $\mathrm{B} 6$ and $\mathrm{E} 8$ associated wit? the crossing of the $\mathrm{L}$ and $E$ helices [18].

Altholigh E7 in C. elegans cannot be occupied by the usual Flis, the alignment is notably strong from E2 though E18. Moreover, the observed Gln at E7 is, in invertebrates, the most frequently seen alternative at this position $[19,20]$.

The $G$ helix is unusual in having two Trp residues at G5 and G9. However, alignment in the $G$ helix is strengthened by the confidence with which we can lo- 


\begin{tabular}{|c|c|c|c|c|c|c|c|c|c|c|c|}
\hline \multirow[b]{2}{*}{ 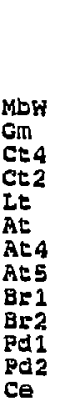 } & \multicolumn{2}{|c|}{ 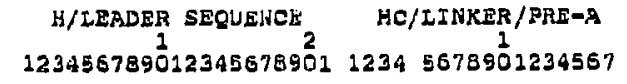 } & 123456789 & 123456 & $\begin{array}{l}A B \\
1234567\end{array}$ & $1234567890^{2}$ & 3456 & 223 & 4567 & 200 & 2834567 \\
\hline & \multicolumn{2}{|c|}{ 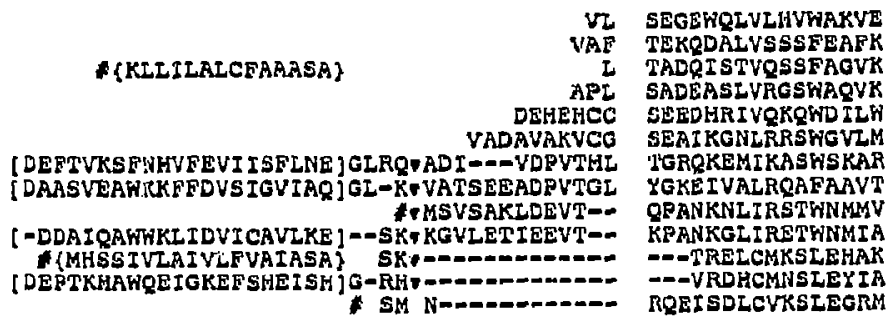 } & \multicolumn{2}{|c|}{ 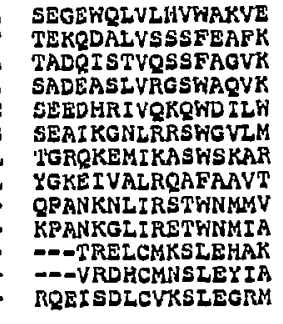 } & 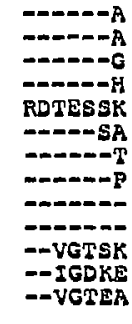 & \multicolumn{2}{|c|}{ 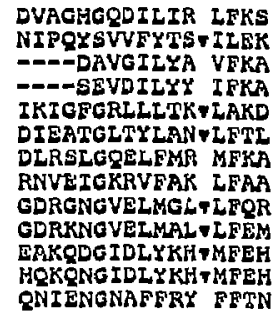 } & \multicolumn{2}{|c|}{$\begin{array}{l}\text { HPETLEK } \\
\text { APAAKDL } \\
\text { DPSIOAK } \\
\text { NPDIMAK } \\
\text { IPDVNDL } \\
\text { RPDTKTY } \\
\text { HPEYQTL } \\
\text { HPEYKNL } \\
\text { APDSKID } \\
\text { APDSKKD } \\
\text { YPAMKKY } \\
\text { YPHMRKA } \\
\text { FPDLRVY }\end{array}$} & 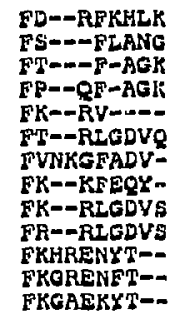 & $\begin{array}{l}\text { TEAEMKA } \\
\text {-VDET-- } \\
\text { DLDSIKO } \\
\text { DLETLKG } \\
\text { DIEHAE- } \\
\text { KGKA-- } \\
\text { PLVSLRE } \\
\text { SVEELPS } \\
\text {-AENIPX } \\
\text {-PSNIPN } \\
\text {-PADVQK } \\
\text {-ITEDVQK } \\
\text {-AODVKK }\end{array}$ \\
\hline & 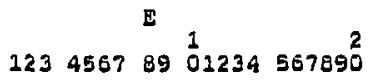 & $\begin{array}{c}\mathrm{EF} \\
1234567890123\end{array}$ & 1234567890 & & $123455^{6}$ & 0123456789 & 12345 & & 123 & 6789012345 & 8901 \\
\hline 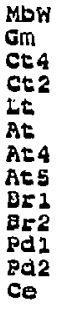 & 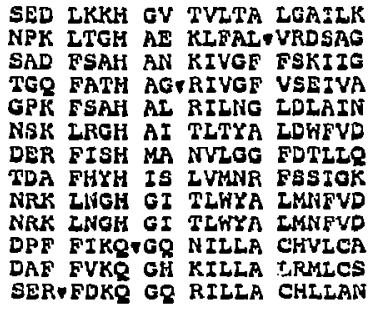 & 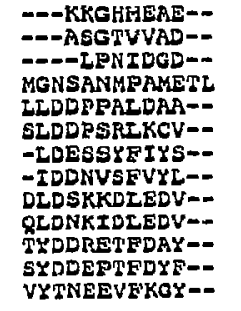 & $\begin{array}{l}\text { IKPLAQSHAT } \\
\text {-ARLGSVHAQ } \\
\text { VTTFVASHTP } \\
\text { IKOMAANHKA } \\
\text { IDHLAHQHEV } \\
\text { VEKEAVNHIN } \\
\text { IRNLGDAHIQ } \\
\text { IKKLCREHIK } \\
\text { CRKFAVNHVI } \\
\text { CRKFAVNHVN } \\
\text { VGELMARHER } \\
\text { VDALMDRHIK } \\
\text {-RETINRHRI }\end{array}$ & 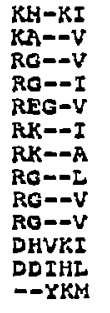 & 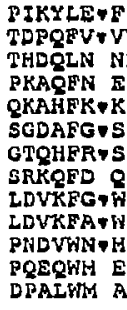 & 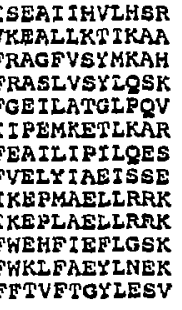 & 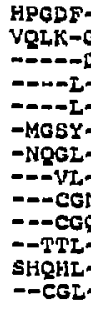 & 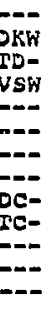 & $\begin{array}{l}\text { GADA } \\
\text { SDEL } \\
\text { FACA } \\
\text { NDSL } \\
\text { DQYD } \\
\text { SDDV } \\
\text { DAAS } \\
\text { SDTO } \\
\text {-DDA } \\
\text { TDQH } \\
\text { DEPT } \\
\text { TEAE } \\
\text { NDQO }\end{array}$ & 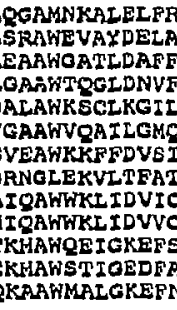 & $\begin{array}{l}\text { KDIAA } \\
\text { AAIKK } \\
\text { GMVEA } \\
\text { NMMFS } \\
\text { TKISE } \\
\text { NAVLS } \\
\text { OVIAQ } \\
\text { CVIEQ } \\
\text { AVLKR } \\
\text { AVLEE } \\
\text { HEISH } \\
\text { HEADK } \\
\text { AESQT }\end{array}$ \\
\hline & $12345678901234567890^{2}$ & & & & & & & & & & \\
\hline 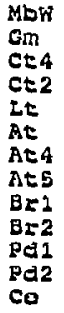 & $\begin{array}{l}\text { KYKELGYQO } \\
\text { A } \\
\text { KM } \\
\text { YL } \\
\text { RLNA } \\
\text { AL } \\
\text { GLKV } \\
\text { GL } \\
\text { SK } \\
\text { KK } \\
\text { H } \\
\text { HAKAEKDHLEGEAREEHH } \\
\text { HLKNSNLFHV }\end{array}$ & & & & & & & & & & \\
\hline
\end{tabular}

Fig. 1. Alignment of non-vertebrate globin sequences showing the intron locations. Sequences were aligned using FASTA [9] and the template of Bashford et al. [10]. $\nabla ;=$ intron position; $\#=$ preceeds coding sequence; \{\}$=$ leader sequence; []$=\mathrm{H}$ helix of preceeding repeat $\mathrm{Mb}=\mathrm{Sperm}$ whale myoglobin [1]. $\mathrm{Gm}=G$ lycine maximu globin [14,33]. $\mathrm{Ct4}=$ Chironomus thummi globin IV [11,32]. Ct2 = Chironomus thumtmi globin IIb [11,27]. $\mathrm{Ll}=$ Lumbricus terrestris globin [12]. At = Anatara trupesia minor globin [13,31]. AT4 = Ariemia globin repeat T4 [17,23]. ATs = Artemia globin

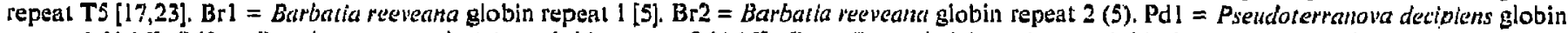
repeat $1[4,16]$. Pd2 $=$ Pseudoterianova decipiens globin repeat $2[4,16]$, Ce $=$ Caciorlabbditis elugans globin $[6,7]$. (Deduced from genomic DNA sequence data oblained as a partial result of the C. elegans genome sequencing project (cosmid zk 637; PIR/NBRF Accesion number [39344) [0,7]).

cate F8 His and its flanking sequence to one side, and the $\mathrm{H}$ helix with its characteristic H8 Trp to the other side. The steric compensation of the bulky side chain of G9 Trp by the single hydrogen side chain of H12 Gly has been discussed previously $[17,21]$. The alignment in Fig. 1 is in accordance with Dixon et al. [4] but the unconventional nature of the S-residue $A B$ turn is further discussed below with the interpretation of the intron structure.

\section{ORGANIZATION OF GLOBIN GENES}

Cosmid $\mathrm{zk} 637$ has an insert sequence that can be identified as giobin like $[6,7]$. Analysis of this putative globin gene confirms the presence of a TATAA, a CAATA and a polyadenylation signal sequence as well as start and stop codons; therefore it contains the neces- sary elements of a functional gene. A single intron of 298 bases is present, having the characteristic nematode splicing consensus sequences [22] (Figs. 1 and 2).

The T4 repeat gene of Artemia globin contains a single intron of about 1,000 bases, in addition to inter. domain introns located between domains $T 3$ and $T 4$ and between T4 and T5 (Figs. 1 and 2). All introns show the consensus splicing sequences [23].

Having correlated the gene sequence data with structurai features of the protein, we can now evaluate the intron locations. Two classes of intron location are recognized, namely (A) intra-repeat and (B) inter-repeat.

\section{1. intra-repeat introns}

The intron positions in invertebrate globin $B$ and $G$ helices, determined so far, are precisely conserved at the $B 12 / B 13$ and the G6/G7 location (Fig. 1). In contrast 
A. CAENORHABDTIS ELEGANS OLOBIM OEIE.

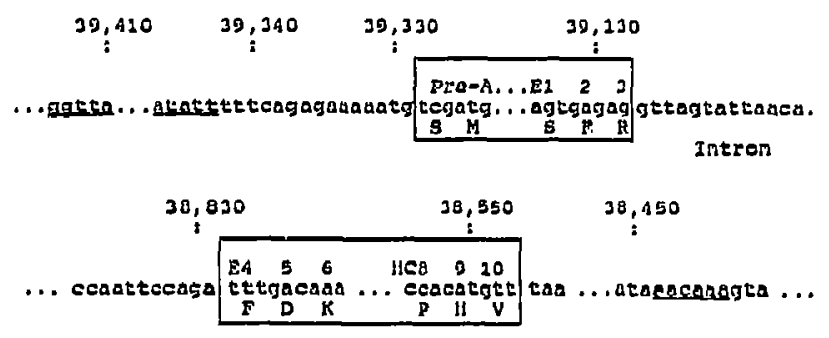

B: ARTEHIA T3/T4/TS GLOBIM OEHE REPEATB.

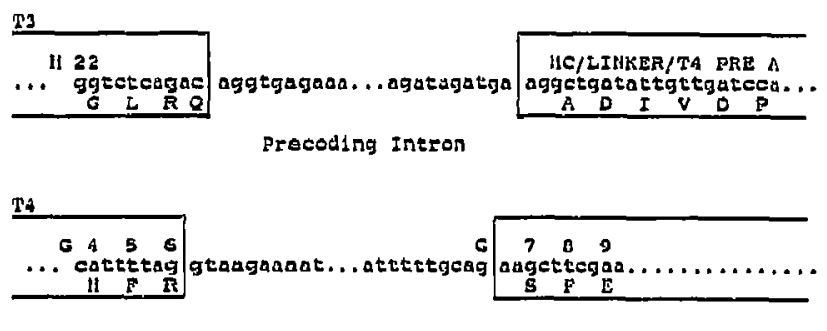

Intra repeat Intron

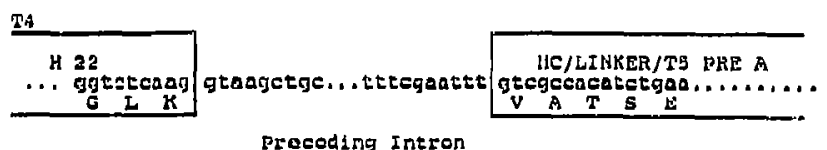

Fig. 2. Gene organization of the $C$. elegans globin and of repeat T4 of Artemia. (A) Partial nucleotide sequence of the $C$. elegans globin gene showing regulatory siles (underlined) anú splice junctions. Exons are boxed. Numbers refer to the sequence of the template strand insert in cosmid zk $637[6,7]$. Deduced coding strand sequence is shown for convenience. Helix notification as in Fig. 1. Amino acids are given by the single letter code underneath the second base of each codon. (B) Partial nucleotide sequence of $A$ rtemia $\mathrm{T} 3 / \mathrm{T} 4 / \mathrm{T} 5$ globin repeats showing splice junctions. Exons are boxed. Helix notifiention as in Fig. 1.

the location of the intron within the E helix seems to be variable. The central intron in plants is inserted at E1415 , which is 4 residues atter the position predicted by Go $[24,25]$. This intron separates the haem binding region into two structural units, F2 and F3 that make contact with haem from opposite sides [24]. In P. decipiens the equivalent central intron is inserted at E7-E8 (CAA/Q G[intron]GT/G CAA/Q) [24]. The equivalent C. elegans intron is inserted at a still more anterior position E3-E4. It is tempting to speculate that it has migrated secondarily from its ancestral more distal position, which from E7 now reads: (CAA/Q GGC/G $\mathrm{CAA} / \mathrm{Q}$ ) and is coincident with the splice site in the $P$. decipiens gene. Similar intron sliding is observed in other genes such as triose phosphate isomerase [26]. In these two globins the nucleotide sequences differ by only one base in this region.

intron insertion may differ by as much as six codons [2], however the conservation of the insertion positions in the $B$ and $G$ helices contrasts with the variation in the E helix.
In contrast to all other Chironomus globin genes sequenced so far, a single intron is present within the E helix (E9-E10) of the gene coding for globin IIB $[1,2,27]$

Single introns are also present in the $B$ helix of $P$. decipiens repeat 2 and in the G-helix of Artemia repeat T4 [23].

\subsection{Inter-repeat ittirons}

In addition to the intra-repeat introns described above, the multi-repeat globin genes of Artemia, Barbatia and Pseudoterranova have inter-repeat introns separating the individual globin units (Fig. 1). From an evolutionary point of view, intra- and inter-repeat introns are not equivalent. Intra-repeat introns represent functional regions of the protein in the sense of the mini-gene hypothesis of Gilbert [28] and thus refer to the primordial gene organization. Inter-repeat introns have accompanied gene duplication events and can thus be considered as secondarily acquired and much more recent.

The presence of inter-repeat introns may help us to assign structure to the N-terminal region of the nematode sequences, which align well with each other but are difficult to reconcile with other globins in the $A$ helix and $A B$ turn. A 5-residue AB turn is not known structurally in globins and the resulting alignment places an intron illogically in the A-helix [4]. The emerging precedent is for introns to be located between functional repeats, e.g. in the Artemia globin gene at both ends of domain $T 4$ where the clear alignment of the $H$ and $A$ helices and the length of the linkers leave no doubt that this is the case. An attractive alignment is obtained by modelling the nematode sequences on Chirononius globin III in which the start of the B helix is shortened by 4 residues (Table I). This places favourable AsX residues at the start of the $B$ helix and logically positions the inter-repeat intron before an inter-repeat linker of about 6 residues

\section{GLOBIN GENE EVOLUTION}

The globin gene organization found in invertebrates is compatible with the idea of an ancestral gene containing 4 exons and 3 introns, with a tendency for introns to have been lost during evolution (Fig. 3) $[1,2]$. This arrangement appears to have been retained in known plant globins and in the first repeat of the $P$. decipiens gene whereas all introns except one have been secondarily deleted from the second repeat. Only a single intron has been retained in the $E$ helix of $C$. elegans and in the Chironomus IIb gene. This intron is equivalent to the ancestral and plant central introns.

It might be argued that these introns are a more recent acquisition and that the ancestral globin gene contains two introns only (in the $B$ and $G$ helices). However novel intron insertion would be opposed to the general evoiutionary tendency of intron reduction. 


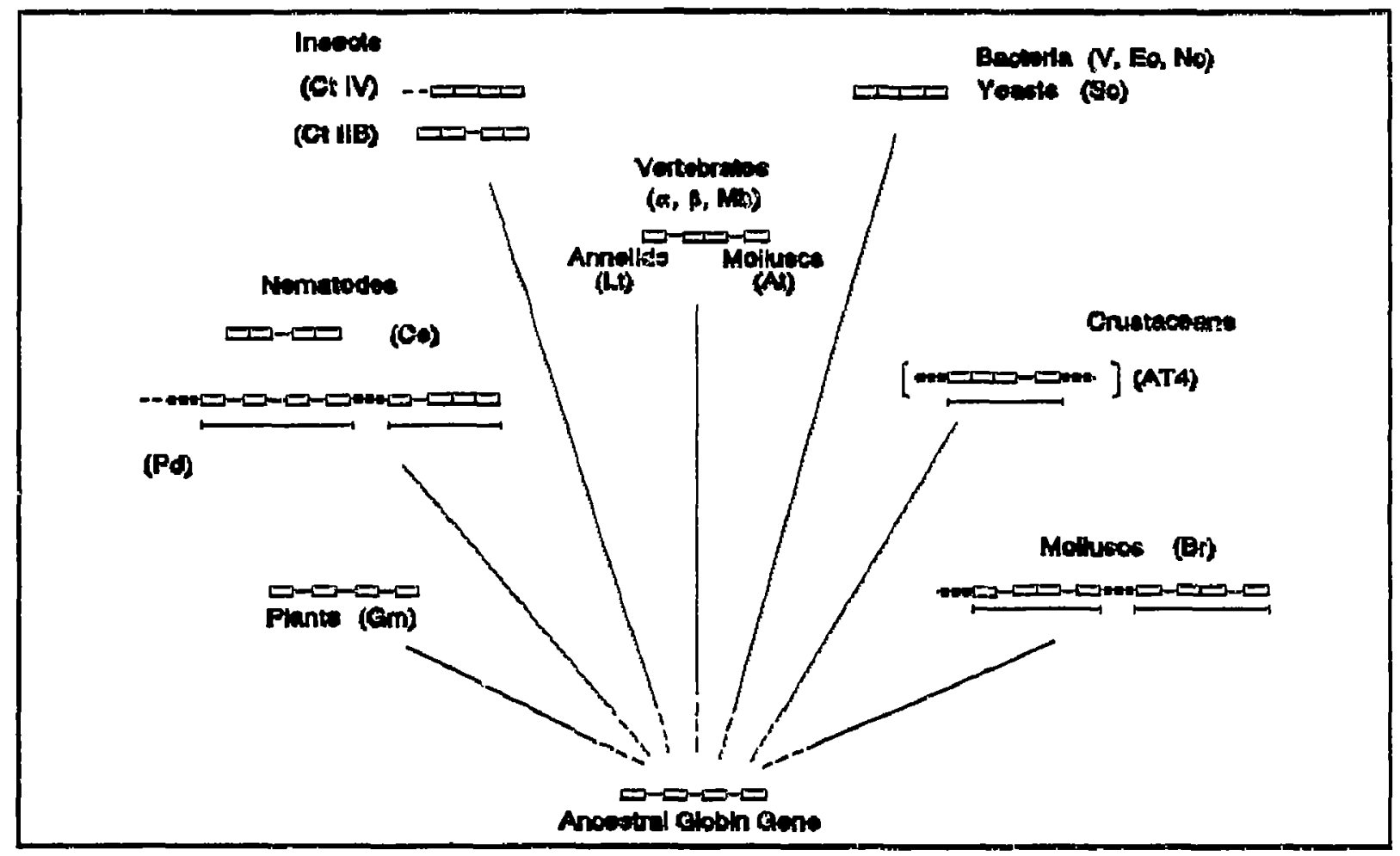

Fig. 3. Evolution of globin gene arrangement. This figure illustrates how the array of globin gene struetures found in extant species can all be derived from a single ancestral 4 exon/3 intron con-figuration. A general tendency of rejecting introns is obvious. Note that the diagram depicted is not a phylogenetic representation. Signal sequences $=\ldots$.. Exon $=$ closed box. Intron: intra-repeat intron $=\ldots$.., Inter-repeat intron $=. . .-$. In multi-repeat structures the repeats are underlined. Vertebrates $(\alpha, \beta, \mathrm{Mb})[2]$. Bacteria $(\mathrm{V}=$ Vitreoscilla) $[34] .(\mathrm{Ec}=$ Echerichia coli) [30]. (Nc $=$ Nostoc commine)

[35]. Ycast ( $\mathrm{Se}=$ Saccharomyces cerevesiae) [29]. Other abbreviations as in Fig. 1.

Moreover, the occurrence of the central intron conceivably hinders the concerted evolution of the haem binding region. Therefore, it is more likely that it would be eliminated in the course of evolution instead of being acquired.

The conservation of intra-repeat introns in the $B$ and $G$ helices of Pseudoterranova (repeat 2) and Artemia (T4) genes at the conserved positions supports their derivation from the ancestral pattern (Fig. 3). Intron deletion in the globins of bacteria, yeasts and Chironorius (except $I T b$ ) has reached the stage where there are none left $[2,29,30,35]$.

The ancestral $\mathbf{H b}$ molecule was presumably an intracellular molecule, since it is present in yeasts, bacteria and protozoa. Derivation of extracellular globins would have required particular adaptations: e.g., the recruit-

Table I

Alternative alignment of nematode $A$ and $B$ helices based on the location of inter-repent introns

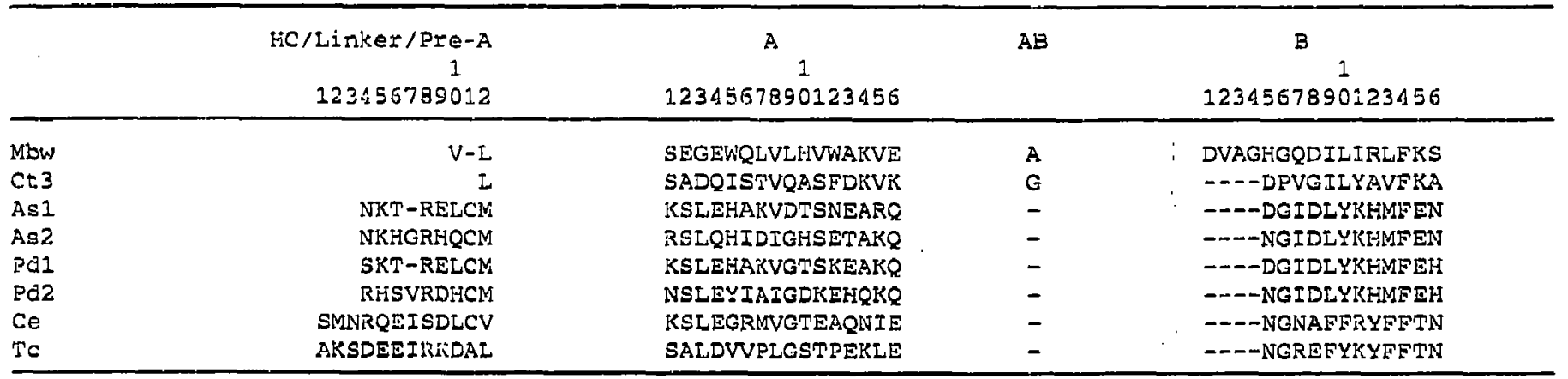

C.3, Chironomus III; Asl and 2, Ascaris summ repeat $I$ and 2; Te, Trichostrongylus colubriformis globin (36); rest of abbreviations as in Fig. 1. 
ment of a leader sequence and an increase in $M_{\mathrm{r}}$ to minimise excretion.

The equivalence of the inter-repeat introns suggests that they are derived from an original intron separating the leader sequence from the globin coding sequence. A potential mechanism has been described for the Barbatia globin gene [5].

Acknowledgements: We thank Dr. Waterston and Dr. Sulsing for making the $C$. elegans globin gene sequence availuble to us belire publication. The Belgian National Science Foundation (NFWO) is greatl: : :knowledged for grants to JV and LM. CNAT thanks the N2 lottery grants board and AJM thanks the NZ health research council for grants.

\section{REFERENCES}

[1] Dickerson, R.E. and Geis, I. (1983) in Hemoglobin: Siructure, Function, Evolution and Pathology (Dickerson, R.E. and Geis, I., Eds.) Benjamin Cummings, Menlo Park, California.

[2] Hardison, R.C. (1991) in Evolution at the Molecular Level (Selander, R.K., Clark, A.G. and Whittam, T.S., Eds.) Pp. 272-290, Sinauer Associates, Sunderland.

[3] Lewin, R. (1985) Seience, 226, 328.

[4] Dixon, B., Walker, B., Kimmings, W. and Pohajdak, B. (1992) J. Mol. Evol. 35, 131-136.

[5] Naito, Y., Riggs, C., Vandergon, T.L. and Riggs, A. (1991) Proc. Natl. Acad. Sci. USA 88, 6672-6676.

[6] Sulston, J., Du, Z., Thomas, K., Wilson, R., Hillier, L., Staden, R., Halloran, N., Green, P., Thierry-Mieg, J., Qiu, L., Dear, S., Coulson, A., Craxton, M., Dirbin, R., Berks, M., Metzstein, M., Hawkins, T., Ainscough, R. and Waterston, R. (1992) Nature $356,37-41$

[7] Waterston, R. (1991) (personal communication).

[8] Bray, J.A. (1991) MSc Thesis, University of Otago

[9] Pearson, W.R. and Lipman, D.J. (1988) Proc, Natl. Acad. Sci. USA 85, 2444-2448.

[10] Bashford, D., Chothia, C. and Lesk, A.M. (1987) J. Mol. Biol. $190,199-216$

[11] Goodman, M., Braunitzer, G., Kleinschmidt, T. and Aschauer, M. (1983) Hoppe-Seyler's Z. Physiol. Chem. 364, 205-217.

[12] Jhiang, S.M. and Riggs, A.F. (1989) J. Biol. Chem. 264, 1900319008.

[13] Fisher, W.K., Gilbert, A.T, and Thompson, E.O.P. (1984) Aust. J. Biol. Sci. 37, 191-203.
[14] Vainstein, B., Harutyunyan, E., Kuranova, I.P., Borisov, V.V. Sosfenovn N.I., Pavlovsky, A.G., Grebenko, A.I. and Nebrasov, Y.B. (1978) Kristallografiya 23, 517-526.

[15] Riggs, C,K. and Riggs, A.F. (1990) in: Invertebrate Dioxygen Carriers (Préaux, G. Ed.) Leuven University Press, Leuven, Belgium, pp. 57-60.

[16] Dixon, B., Walker, B., Kimmings, W. and Pohajdak, B. (1991) Proc. Natl. Acad. Sci. USA 88, 5655-5659.

[17] Trotman, C.N.A., Manning, A.M., Moens, L. and Tate, W.P. (1991) J. Biol. Chem., 266, 13789-13795.

[18] Richmond, T.J. and Richards, F.M. (1978) J. Mol. Biol. 119, 537-555.

[19] Goodman, M., Pedwaydon, J., Czelusniak, J., Suzuki, T., Goloh, T., Moens, L., Shishikura, F., Walz, D. and Vinogradov, S. (1988) J. Mol. Evol. 27, 236-249.

[20] Pecters, K., De Baere, I. and Moens, L. (1992) in: International Congress on Invertebrate Dioxygen Carriers, Book of Abstracts, II-P07.

[21] De Baere, I., Liu, L., Mosns, L., Van Becumen, J., Gielens, C., Richelle, J., Trotman, C., Finc, J., Gerstein, M. and Perulz, M. (1992) Proc. Nittl. Acad. Sci. USA 89, 4638-4642.

[22] Emmons, S. (1988) in: The Nematode Caenorhabditis elegans, Cold Spring Harbor Laboratory, pp. 47-79.

[23] Jellie, A. (1992) M.Se. Thesis, University of Otago.

[24] Go, M. (1981) Nature 291,90-92.

[25] Go, M. (1983) Proc. Natl. Acad. Sci. USA 80, 1964-1968.

[26] Lewin, B. (1990) Genes IV, Oxford University Press, Niw York and Cell Press, Cambridge, MA.

[27] Kao, W, and Bergstrom, G. (1992) in: Inernational Congress on Invertebrate Dioxygen Carriers, Book of Abstracts, 11-LA.

[28] Gilbert, W. (1987) Cold Spring Harbor Symp. Quant. Biol. 52, 901-905.

[29] Zhu, J. and Riggs, A.F. (1992) Proc. Nall. Acad. Sci. USA 89, 5015-5019.

[30] Vasudevan, S.G., Armarego, W.L.F., Shaw, D.C., Lilley, P.E., Dixon, N.E. and Pcole, R.K. (1991) Moi. Gen. Genet. 226, 40 58.

[31] Titchen, D.A., Glenn, W.K., Nassif, N., Thompson, A.R., and Thiompson, E.O.P. (1991) Biochim. Biophys. Acta 1089, 61-67.

[32] Antoine, $M$. and Niessing. J. (1984) Nature, 310, 795-798.

[33] Hyldig-Nielsen, J., Jenssen, E.O., Paludan, K., Wiborg, O., Garrel, R., Jorgensen, P. and Marker, K.A. (1982) Nucleic Acids Res. $10,689-701$.

[34] Wakabayashi, S., Matsubara, H. and Webster, D.A. (1986) Nature $322,481-48.3$

[35] Potts, M., Angeloni, S.Y., Ebel, R.E. and Bassam, D. (1992) Science 256, 1690-1692.

[36] Frenkel, J.M., Dopheide, T.A., Wagland, B.M. and Ward, C.W. (1992) Mol. Biodiem. Parasitol. 50, 27-36. 